\title{
Tunnelled central venous catheter-induced thrombosis: a rare case of superior vena cava syndrome
}

\author{
Sandeep K. Aggarwal, BSc;* William McCauley, MD, MHPE ${ }^{\dagger}$
}

\begin{abstract}
Thrombotic venous obstruction in patients with a tunnelled central venous catheter is a cause of superior vena cava syndrome that is not routinely encountered by emergency physicians. Diagnosis requires identifying patients at risk (e.g., those under treatment for cancer and those who have a tunnelled central venous catheter), recognizing the signs and symptoms of superior vena cava syndrome, usually dyspnea and dilated neck or thoracic veins, and imaging the venous obstruction using computer tomography or sonography. Management involves anticoagulation and local thrombolytic administration. We report the case of a 28-year-old woman who presented with a 2day history of face, chest and bilateral arm swelling who had been receiving maintenance chemotherapy for acute lymphoblastic leukemia through a Hickman $®$ catheter. This case demonstrates the need to be vigilant for thrombus formation in patients with long-term, indwelling central venous catheters.
\end{abstract}

Key words: tunnelled central venous catheter; catheter-induced thrombosis; anticoagulation; thrombolytics; superior vena cava syndrome

\begin{abstract}
RÉSUMÉ
La thrombose veineuse chez les patients chez qui est installé un cathéter veineux central tunnellisé est une cause de syndrome de la veine cave supérieure que les médecins d'urgence ne rencontrent pas souvent. Le diagnostic nécessite de cibler les patients à risque ( $p$. ex. ceux qui reçoivent un traitement pour un cancer et ceux chez qui est installé un cathéter veineux central tunnellisé), de reconnaître les signes et symptômes du syndrome de la veine cave supérieure, généralement la dyspnée et la dilatation des veines du cou ou du thorax, et le recours à la tomodensitométrie ou à l'échographie pour voir l'obstruction veineuse. La prise en charge comprend l'anticoagulothérapie et l'administration locale d'un thrombolytique. Nous présentons le cas d'une femme âgée de 28 ans qui recevait de la chimiothérapie d'entretien pour une leucémie aiguë lymphoblastique par le biais d'un cathéter Hickman et qui a été reçue à l'urgence pour un œdème au visage, à la poitrine et aux deux bras présent depuis deux jours. Le présent cas illustre le besoin de se montrer vigilant quant à la formation possible de thrombi chez les patients chez qui est installé un cathéter veineux central tunnellisé.
\end{abstract}

\section{Introduction}

In the United States, over 5 million central venous catheters (CVCs) are placed each year by a wide range of medical practitioners. ${ }^{1}$ They are used for hemodynamic monitoring, parenteral nutrition and for the administration

*Schulich School of Medicine, University of Western Ontario, London, Ont.

tDepartment of Emergency Medicine, University of Western Ontario, London Ont.

Received: Nov. 29, 2004; final submission: Apr. 2, 2005 ; accepted: Apr. 23, 2005

This article has been peer reviewed.

Can J Emerg Med 2005;7(4):273-7 
of blood products, chemotherapy and medications. Thus, knowledge of related complications is increasingly important. Emergency physicians are familiar with the immediate complications related to line placement (e.g., hemorrhage, pneumothorax and cardiac arrhythmia); however, the long-term sequelae of surgically tunneled catheters, including thrombosis, pulmonary embolism (PE) and sepsis, have received little attention in the emergency medicine literature. Knowledge of these latter complications is important when assessing patients with these devices, which include the Hickman ${ }^{\circledR}$ and Broviac ${ }^{\circledR}$ (Bard Access Systems, Inc., Salt Lake City, Utah).

\section{Case report}

A 28-year-old woman on week 31 of active maintenance chemotherapy for first remission acute lymphoblastic leukemia presented to the emergency department (ED) with a 2-day history of tight, painful swelling of her face, upper chest and arms. Her most recent chemotherapy treatment, 8 days prior to presentation, was unremarkable. Her maintenance regimen consisted of oral and intravenous (IV) vincristine, methotrexate and mercaptopurine. As well, she had just completed a 5-day course of prednisone. Apart from these she was on no medications. Thinking her facial swelling was a chemotherapy reaction, she took 25 $\mathrm{mg}$ of diphenhydramine every 6 hours, with no improvement. Over the following 2 days, the swelling spread to her upper chest and arms, at which point she was sent to the ED by her family physician. A review of systems revealed no cough, dyspnea, chest pain, anorexia, dysphagia, chills or urinary problems; however, she complained of feeling uncomfortable when lying supine.

On exam, she was alert and ambulatory with normal vital signs. Temperature was $36.2^{\circ} \mathrm{C}$, pulse was 83 beats/min, respiratory rate was 20 breaths/min, blood pressure was $131 / 77 \mathrm{~mm} \mathrm{Hg}$, and oxygen saturation was $95 \%$ on room air. She was plethoric with deep swelling of her face, neck, upper torso and both arms. Her chest was clear on auscultation, and it was noted she had a right-sided subclavian Hickman ${ }^{\circledR}$ catheter, which had been inserted 1 year earlier to facilitate the delivery of her chemotherapy. Her heart sounds were normal, and her abdomen was soft and nontender with no evidence of mass or organomegaly.

Complete blood cell count, electrolytes, blood glucose, renal function and coagulation profile were within normal limits except for an elevated white blood cell count, at 13 600/cc with neutrophilia. Of note, hemoglobin and platelet counts were normal, at $134 \mathrm{~g} / \mathrm{L}$ and $179000 / \mathrm{cc}$, respectively. A peripheral blood smear revealed circulating blasts, polychromasia and "tear drop" erythrocytes, but no evidence of blast crisis. The patient's International Normalized Ratio (INR) and partial thromboplastin time were $1.0 \mathrm{sec}$ and $22 \mathrm{sec}$, respectively.

Results of a chest x-ray were unremarkable, with no evidence of pneumothorax, consolidation, tracheal deviation, pleural effusion or mediastinal widening. Computed tomography (CT) with contrast confirmed the tentative diagnosis of superior vena cava (SVC) obstruction, showing absent filling of the brachiocephalic vein and SVC consistent with SVC thrombosis (Fig. 1). There was no evidence of mediastinal, hilar adenopathy or space-occupying lesion.

Since her swelling had decreased enough for her to comfortably lay flat, she did not require hospitalization. Hematology follow-up was arranged, and she received daily injections of low-molecular-weight heparin (LMWH) (dalteparin sodium, $12000 \mathrm{IU}$ ) for 7 days, as well as oral warfarin, to be continued as long as her Hickman ${ }^{\circledR}$ catheter remained in place. She was told to return to the ED if she had any difficulties. Within 48 hours, the swelling improved markedly and she felt more comfortable. She showed no signs of bleeding, and her INR at one week was $2.6 \mathrm{sec}$. To prevent recurrent thrombosis, plans were made to remove her Hickman ${ }^{\circledR}$ line after completion of her maintenance chemotherapy.

\section{Discussion}

The SVC returns blood from the head, neck, upper extrem-

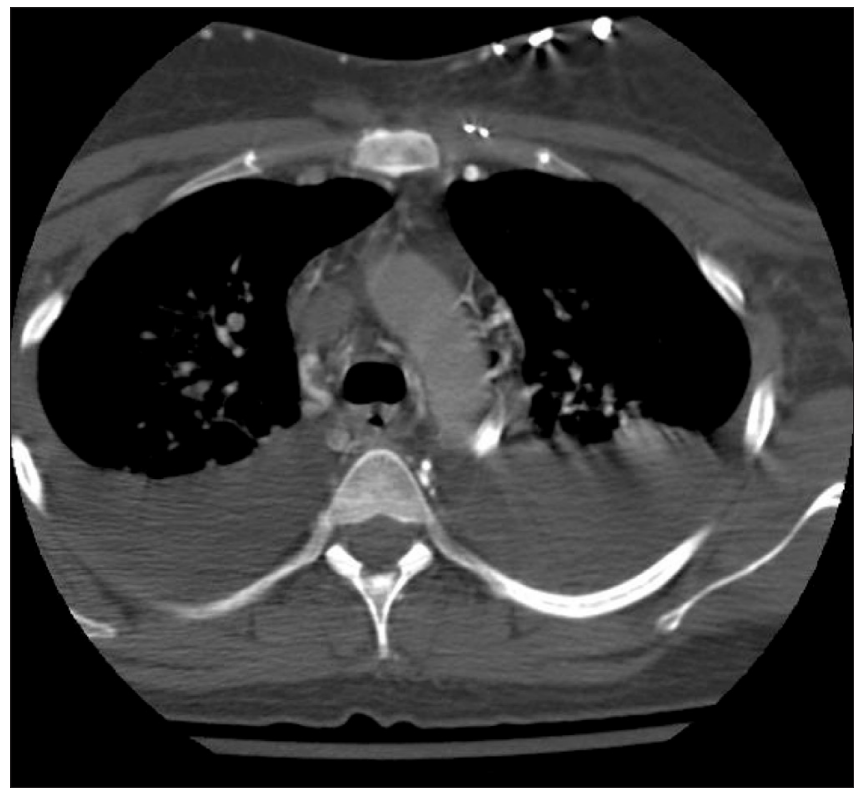

Fig. 1. Results of the CT of the chest with contrast, showing an absence of filling of the brachiocephalic vein and superior vena cava (SVC), consistent with thrombosis of the SVC. 
ities and posterior trunk (via the azygous vein) to the right atrium. Superior vena cava syndrome (SVCS) is defined as any obstruction of the SVC that causes symptoms such as swelling and dyspnea. SVCS is a medical emergency mandating immediate assessment and treatment.

SVCS was first described by Hunter in 1757 as a complication of syphilitic aortic aneurysm..$^{2}$ In 1954 , Schechter reported that $40 \%$ of SVCS cases were related to aortic aneurysms and infections like syphilis and tuberculosis, although the pathophysiological mechanism was unclear. ${ }^{3}$ As the prevalence of these diseases declined, malignancy became the major cause of SVCS. Today, an estimated 15000 people a year in the US develop SVCS, and $85 \%$ to $97 \%$ of these cases are associated with malignancy. ${ }^{4}$

Risk factors for CVC-induced thrombosis include venous stasis, vascular endothelial injury and hypercoagulability. Cancer patients who require central venous access often have a hypercoagulable state, and CVC placement may damage the low-pressure venous system, inciting clot formation. Four studies ${ }^{5-8}$ suggest that venous catheters placed via the left subclavian route are more likely to cause thrombosis than those placed from the right. In one of these studies, the proportion of left-sided and right-sided CVC-induced thrombosis was found to be as high as $87 \%$ and $62 \%$, respectively. ${ }^{5}$ The position of the catheter in the venous system is also a significant factor in CVC thrombosis. Lines placed high in the SVC are associated with greater risk than those at the cavo-atrial junction, possibly due to a higher likelihood of vascular endothelial damage in the cephalad position. ${ }^{9-11}$

Venographic studies performed after line placement suggest that $12 \%-87 \%$ of all patients with CVCs develop vascular thrombi. Of these, an estimated 29\% (range, $5 \%-62 \%$ ) develop asymptomatic clots and 12\% (range, $4 \%-54 \%$ ) develop symptomatic clots. ${ }^{12}$ Moreover, $68 \%-98 \%$ of CVC-induced thrombi will occur within the first 30 days after insertion. ${ }^{5,13,14}$

\section{Clinical presentation}

The clinical picture evolves gradually; most patients won't seek medical attention in the first week. The most common symptoms in SVCS are dyspnea (50\%), cough (20\%), chest pain (20\%) and dysphagia (20\%); the most common signs are dilated thoracic $(70 \%)$ or neck $(60 \%)$ veins, facial $(45 \%)$ or arm or trunk (40\%) swelling and cyanosis $(15 \%) .{ }^{15}$ The severity and rapidity of symptom onset depends largely on whether the obstruction is distal or proximal to the entry of the azygous vein, with more proximal clots causing more abrupt and severe symptoms. ${ }^{16}$
Pulmonary embolism and sepsis are the major complications of SVC thrombosis. Approximately 6\% (range, $2 \%-14 \%)$ of patients with CVC-induced upper-extremity deep-vein thrombosis (DVT) develop symptomatic PE, and an additional 5\% (range 3\%-15\%) develop asymptomatic PE. These rates are significantly less than rates of asymptomatic PE from lower extremity DVT. ${ }^{12}$ While heparin is recommended to prevent $\mathrm{PE}$ after upper extremity DVT, there are few data looking at the value of heparin for SVCS-related PE, and additional studies are needed. ${ }^{17-19}$

The incidence of sepsis in tunnelled CVC-induced thrombosis is about $23 \%$ (range $18 \%-38 \%$ ), primarily due to Staphylococcus epidermidis from adjacent skin, or gramnegative enteric bacilli from the gastrointestinal tract. ${ }^{12}$

\section{Diagnosis}

The diagnosis of SVCS is based mainly on clinical findings, particularly dyspnea and dilated neck or upper extremity veins. A chest $\mathrm{x}$-ray is valuable and may provide evidence of pneumonia, lung or mediastinal pathology, or $\mathrm{PE}$, either as a primary diagnosis or a complication of SVC thrombosis. Fever, chills, tachycardia, tachypnea, leukocytosis or leukopenia suggest the need for blood and urine cultures, because sepsis is also a common complication of SVCS. Coagulation studies may reveal clotting abnormalities, and spiral CT or ventilation-perfusion scanning may be required to rule out $\mathrm{PE}$, another common complication.

Contrast venography has been used historically to confirm thrombotic occlusion; however, recent reports show that transesophageal echocardiography, duplex sonography and contrast CT are sufficiently accurate. ${ }^{20,21}$ If indicated, thrombolytic therapy can be instituted based on the CT or sonographic findings alone..$^{22}$ Magnetic resonance imaging combined with venography provides excellent visualization of the central veins, ${ }^{23,24}$ but limited access to this modality minimize its use. In cases where the results of chest $\mathrm{x}$-ray suggest a mediastinal mass, confirmatory chest CT with contrast may be the only other imaging modality required to diagnose SVCS. ${ }^{15,25}$ If the cause of SVCS is thought to be local malignancy rather than thrombus, urgent referral for biopsy and histology is required before radiotherapy and chemotherapy can be instituted.

\section{Treatment}

Prophylactic anticoagulation may be indicated to prevent CVC-induced thrombosis; however, the preferred modality - low-dose warfarin or LMWH - is controversial. The 2000 American College of Chest Physicians guidelines rec- 
ommend low-dose warfarin $(1 \mathrm{mg} / \mathrm{d})$ or once-daily LMWH for prophylaxis. ${ }^{26}$ These recommendations were based on previous literature; ${ }^{10,26-28}$ however, more recent studies suggest these regimens may be of little or no benefit; ;9,30 Larger, placebo controlled trials are required to resolve the issue.

In the acutely symptomatic patient with suspected CVCinduced SVCS, the thrombolytic agents rt-PA, urokinase and streptokinase are 73\%-97\% effective and have minimal risk of significant adverse events, such as intracranial or gastrointestinal hemorrhage, if they are given within 2 days of thrombosis. These agents are most successful when delivered directly to the centre of the thrombus using the tunnelled CVC itself rather than infused peripherally ${ }^{31-39}$ In addition, anticoagulation with LMWH may be instituted to slow thrombus propagation. Once initiated, this should be maintained until follow-up with a hematologist and resolution of symptoms. There is no evidence that removing the catheter in the ED provides any benefit and, since no studies have clarified the risk of PE associated with immediate CVC removal, the central catheter can remain in place to facilitate treatment and the decision to remove it can be deferred. Immediate removal may be considered in cases of catheter-induced sepsis if the catheter is no longer needed; however no data are available to guide this decision. ${ }^{40}$

Continued research is needed to better understand this disease and its management. Future long-term studies should address the value of anticoagulation for prevention of SVCS, the optimal thrombolytic agent for confirmed thrombosis, and the incidence of complications associated with catheter removal, especially in the context of catheterinduced septic thrombus.

\section{Conclusion}

Patients with SVCS typically present with dyspnea, dilated neck or thoracic veins, and swelling of the face and upper extremities. This condition is usually due to malignancy, but it may also occur because of local thrombus formation. Patients with indwelling CVCs are at significant risk of thrombosis and SVCS.

Competing interests: None declared.

\section{References}

1. Moureau N, Poole S, Murdock MA, Gray SM, Semba CP. Central venous catheters in home infusion care: outcomes analysis in 50,470 patients. J Vasc Interv Radiol 2002;13:1009-16.

2. Schechter MM. The superior vena cava syndrome. Am J Med Sci 1954; 227:46-56.
3. Hunter W. The history of an aneurysm of the aorta with some remarks on aneurysms in general. Med Obstet Soc Phys (London) 1757;1:323.

4. Wudel JL Jr, Nesbitt JC. Superior vena cava syndrome. Curr Treat Options Oncol 2001;2:77-91.

5. De Cicco M, Matovic M, Balestreri L, Panarello G, Fantin D, Morassut S, et al. Central venous thrombosis: an early and frequent complication in cancer patients bearing long-term silastic catheter. A prospective study. Thromb Res 1997;86:101-13.

6. Cimochowski GE, Worley E, Rutherford WE, Sartain J, Blondin J, Harter H. Superiority of the internal jugular over the subclavian access for temporary dialysis. Nephron 1990;54:154-61.

7. Puel V, Caudry M, Le Metayer P, Baste JC, Midy D, Marsault C. Superior vena cava thrombosis related to catheter malposition in cancer chemotherapy given through implanted ports. Cancer 1993;72:2248-52.

8. Stanislav GV, Fitzgibbons RJ Jr, Bailey RT Jr, Mailliard JA, Johnson PS, Feole JB. Reliability of implantable central venous access devices in patients with cancer. Arch Surg 1987;122: $1280-3$.

9. Schwarz RE, Coit DG, Groeger JS. Transcutaneously tunneled central venous lines in cancer patients: an analysis of device-related morbidity factors based on prospective data collection. Ann Surg Oncol 2000;7:441-9.

10. Nightingale CE, Norman A, Cunningham D, Young J, Webb A, Filshie J. A prospective analysis of 949 long-term central venous access catheters for ambulatory chemotherapy in patients with gastrointestinal malignancy. Eur J Cancer 1997;33:398-403.

11. Namyslowski J, Trerotola SO, McKusky M, Johnson MS, Shah $\mathrm{H}$, Kraus M. Retrospective analysis of blood flow rates via tunneled right and left internal jugular vein dialysis catheters. Cardiovasc Intervent Radiol 1999;22 (suppl 2):S91.

12. Kuter DJ. Thrombotic complications of central venous catheters in cancer patients. Oncologist 2004;9:207-16.

13. Curelaru I, Bylock A, Gustavsson B, Hultman E, Linder LE, Stefansson T, et al. Dynamics of thrombophlebitis in central venous catheterization via basilic and cephalic veins. Acta Chir Scand 1984;150:285-93.

14. Lokich JJ, Becker B. Subclavian vein thrombosis in patients treated with infusion chemotherapy for advanced malignancy. Cancer 1983;52:1586-9.

15. Markman M. Diagnosis and management of superior vena cava syndrome. Cleve Clin J Med 1999;66:59-61.

16. Sculier JP, Feld R. Superior vena cava obstruction syndrome: recommendations for management. Cancer Treat Rev 1985;12: 209-18.

17. Hoch JR. Management of the complications of long-term venous access. Semin Vasc Surg 1997;10:135-43.

18. Lowell JA, Bothe A Jr. Central venous catheter related thrombosis. Surg Oncol Clin North Am 1995;4:479-92. 
19. Adelstein DJ, Hines JD, Carter SG, Sacco D. Thromboembolic events in patients with malignant superior vena cava syndrome and the role of anticoagulation. Cancer 1988;62:2258-62.

25. Wudel JL Jr, Nesbitt JC. Superior vena cava syndrome. Curr Treat Options Oncol 2001;2:77-91.

20. Weber T, Huemer G, Tschernich H, Kranz A, Imhof M, Sladen RN. Catheter-induced thrombus in the superior vena cava diagnosed by transesophageal echocardiography. Acta Anaesthesiologica Scandinavica 1998;42:1227-30.

21. Nazarian GK, Foshager MC. Color Doppler sonography of the thoracic inlet veins. Radio Graphics 1995;15:1357-71.

23. Demondion X, Boutry N, Drizenko A, Paul C, Francke JP, Cotton A. Thoracic outlet: anatomic correlation with MR imaging. Am J Roentgenol 2000;175:417-22.

24. Shinde TS, Lee VS, Rofsky NM, Krinksy GA, Weinreb JC. Three-dimensional Gadolinium-enhanced MR venographic evaluation of patency of central veins in the thorax: initial experience. Radiology 1999;213:555-60.

22. Chen JC, Bongard F, Klein SR. A contemporary perspective on superior vena cava syndrome. Am J Surg 1990;160:207-11.

26. Hirsh J, Dalen J, Guyatt G. The sixth (2000) ACCP guidelines for antithrombotic therapy for prevention and treatment of thrombosis. American College of Chest Physicians. Chest 2001;119 (suppl):1S-2S.

27. Bern MM, Lokich JJ, Wallach SR, Bothe A Jr, Benotti PN, Arkin CF, et al. Very low doses of warfarin can prevent thrombosis in central venous catheters. A randomized prospective trial. Ann Intern Med 1990;112:423-8.

28. Boraks P, Seale J, Price J, Bass G, Ethell M, Keeling D, et al. Prevention of central venous catheter associated thrombosis using minidose warfarin in patients with haematological malignancies. Br J Haematol 1998;101:483-6.

29. Montreal M, Alastrue A, Rull M, Mira X, Muxart J, Rosell R, et al. Upper extremity deep venous thrombosis in cancer patients with venous access devices - prophylaxis with a low molecular weight heparin (Fragmin). Thromb Haemost 1996;75:21-3.

30. Eastman ME, Khorsand M, Maki DG, Williams EC, Kim K, Sondel PM, et al. Central venous device-related infection and thrombosis in patients treated with moderate dose continuous- infusion interleukin-2. Cancer 2001;91:806-14.

31. Heaton DC, Han DY, Inder A. Minidose (1 mg) warfarin as prophylaxis for central vein catheter thrombosis. Intern Med J 2002;32:84-8.

32. Teichgräber UK, Gebauer B, Benter T, Wagner HJ. Central venous access catheters: radiological management of complications. Cardiovasc Intervent Radiol 2003;26:321-33.

33. Mewissen MW, Seabrook GR, Meissner MH, Cynamon J, Labropoulos N, Haughton SH. Catheter-directed thrombolysis for lower extremity deep venous thrombosis: report of a national multicenter registry. Radiology 1999;211:39-49.

34. Smith NL, Ravo B, Soroff HS, Khan SA. Successful fibrinolytic therapy for superior vena cava thrombosis secondary to longterm total parenteral nutrition. JPEN: J Parenteral Enteral Nutr 1985;9:55-7.

35. Gray BH, Olin JW, Graor RA, Young JR, Bartholomew JR, Ruschhaupt WF. Safety and efficacy of thrombolytic therapy for superior vena cava syndrome. Chest 1991;99:54-9.

36. Lawson M, Bottino JC, Hurtubise MR. The use of urokinase to restore patency of occluded central venous catheters. Am J Intraven Ther Clin Nutr 1982;9:29-32.

37. Gray RJ, Levitin A, Buck D, Brown LC, Sparling YH, Jablonski $\mathrm{KA}$, et al. Percutaneous fibrin sheath stripping versus transcatheter urokinase infusion for malfunctioning well-positioned tunneled central venous dialysis catheters: a prospective, randomized trial. J Vasc Interv Radiol 2000;11:1121-9.

38. Savader SJ, Ehrman KO, Porter DJ, Haikal LC, Oteham AC. Treatment of hemodialysis catheter-associated fibrin sheaths by rt-PA infusion: critical analysis of 124 procedures. J Vasc Interv Radiol 2001;12:711-5.

39. Whigham CJ, Lindsey JI, Goodman CJ, Fisher RG. Venous port salvage utilizing low dose tPA. Cardiovase Intervent Radiol 2002;25:513-6.

40. McGee DC, Gould MK. Preventing complications of central venous catheterization. N Engl J Med 2003;348(12):1123-33.

Correspondence to: Sandeep K. Aggarwal, 3530 Irwin Crt., Mississauga ON L5L 4W4; 905 820-7693, saggarwal2006@meds.uwo.ca 